\title{
Trace element signatures in larval soft tissues reveal transport, but not population connectivity
}

\author{
Seth H. Miller ${ }^{1, *}$, Steven G. Morgan ${ }^{1,2}$, J. Wilson White ${ }^{3}$, Peter G. Green ${ }^{4}$ \\ ${ }^{1}$ Bodega Marine Laboratory, University of California Davis, Bodega Bay, California 94923, USA \\ ${ }^{2}$ Department of Environmental Science and Policy, University of California Davis, Davis, California 95616, USA \\ ${ }^{3}$ Department of Biology and Marine Biology, University of North Carolina Wilmington, Wilmington, North Carolina 28403, USA \\ ${ }^{4}$ Department of Civil and Environmental Engineering, University of California Davis, Davis, California 95616, USA
}

ABSTRACT: Trace elemental signatures incorporated into calcified structures in fish and mollusk larvae have been used to reveal population connectivity and larval dispersal trajectories. To determine whether trace element analysis could be applied to larvae that do not permanently retain calcified structures, we raised larvae of the porcelain crab Petrolisthes cinctipes from multiple locations along the northern California, USA, coast in a common water source for up to $8 \mathrm{wk}$. We analyzed 20 elements in extractions of soft tissues from embryos and the 2 larval and 1 postlarval stages. Elemental signatures of individuals in each developmental stage were compared to an atlas of signatures from each collection site using discriminant analysis to determine whether larvae could be accurately assigned to their site of origin in 2 ways. First, postlarvae were classified using a natal site atlas constructed using embryonic signatures from each site, and this classification had poor success (average $39.7 \%$ correct). Second, larvae of each stage were classified using a natal site atlas constructed using signatures of larvae from that same stage. This yielded considerably better classification success (81.7\% correct overall). Thus, the same trace element signatures were not consistently maintained from embryos to postlarvae, but differences in signatures among natal sites were maintained during the larval period. Trace element signatures in soft tissues could be useful in tracking dispersal between stages and determining how many sites, rather than which sites, contributed to a cohort of larvae or settlers.

KEY WORDS: Dispersal trajectories - Natal origins · Postlarval settlement · Petrolisthes cinctipes

Resale or republication not permitted without written consent of the publisher

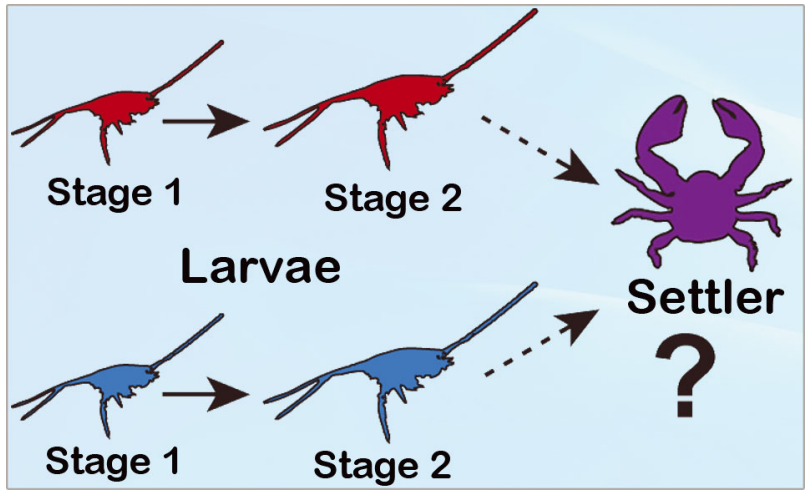

Trace element signatures could correctly assign early stage larvae to a site of origin ('red' vs. 'blue'), but not late stage settlers.

Image: Clayton Lord

\section{INTRODUCTION}

Populations of most species of sedentary marine organisms are connected by the movement of pelagic gametes or larvae, though knowledge of the dispersal patterns of larvae is limited (Strathmann et al. 2002, Marshall \& Morgan 2011). Larvae can be affected by ocean currents, but many species exhibit behaviors that regulate their alongshore and offshore movement (Young 1995, Kingsford et al. 2002, Queiroga \& Blanton 2005), resulting in populations that are less connected than previously thought, even in highly advective ocean environments (Morgan et al. 2009, Shanks \& Shearman 2009, Miller \& Morgan 2013). Determining larval dispersal pathways in the field requires an unambiguous tagging method, but most of the tagging methods commonly used in eco- 
logical studies are inappropriate for tracking marine larvae. Visual tracking of individuals is impossible for all but the largest larvae, and even then for only very short periods of time (Olson 1985, Carlon \& Olson 1993). Artificially tagging larvae is impractical, because the tag must be distinctive, easily applied to millions of individuals, retained for several weeks to months throughout larval development, invisible to predators, non-stressful to larvae, and efficiently recovered from settled juveniles (but see Mohler 1997, Jones et al. 1999, Moran 2000). Instead, investigators have capitalized on differences in naturally occurring trace element signatures of larvae to establish larval dispersal trajectories and population connectivity (Thorrold et al. 2002, 2007).

Natural trace element signatures are created when developing larvae incorporate trace elements into hard calcified structures, such as shells (Becker et al. 2005), statoliths (Zacherl et al. 2003), and otoliths (Swearer et al. 1999) or soft tissues (Anastasia et al. 1998). The signatures are influenced by water chemistry, maternal provisioning, and larval food sources (Hayes 1991, Levin et al. 1993, Anastasia et al. 1998, DiBacco \& Levin 2000, Walther \& Thorrold 2006), though the relative contributions of these factors are poorly understood, particularly for invertebrates. Regardless of the source, there is often considerable variation among spawning locations in the trace element signatures deposited in larval hard and soft tissues. In the case of hard parts, an investigator can isolate the signature from the natal portion of the structure and use the signature to map the larva to its spawning location using an 'atlas' of the signatures from each location. In the case of soft parts, the signature must be retained throughout development to determine natal location. Because of the uncertainty surrounding the retention of natal signatures in larval soft tissues, investigators have focused on studies involving calcified structures (e.g. Swearer et al. 1999, Becker et al. 2007).

Although using trace element signatures found in calcified structures can provide a wealth of information about population connectivity, the technique is currently applicable to only fishes and mollusks, because the vast majority of invertebrates lack hard structures that are large enough to analyze and are retained throughout larval development. Trace elemental signatures in larval soft tissues could be used for all species provided that they are maintained throughout development as larvae travel through different water masses. For example, crab larvae molt their exoskeleton multiple times during the larval period, discarding any natal signatures in them, but they could retain the signature in soft tissues provided that metabolic turnover is slow. Artificially high levels of some trace elements are retained throughout development (Anastasia et al. 1998), and distinctive trace element signatures occur in embryos and recently released larvae (DiBacco \& Chadwick 2001, Carson 2008, Miller et al. 2013). However, it has yet to be demonstrated that larvae maintain stable, natural signatures throughout their entire pelagic development.

Our objective was to determine whether natural trace element signatures are retained in soft tissues from the embryonic to the settlement stage of the porcelain crab Petrolisthes cinctipes. This species is an excellent candidate for trace element studies because (1) embryos are brooded externally and take up trace elements from substrates as well as surrounding waters (Anderson et al. 2006, Smalling et al. 2010), resulting in distinctive signatures along the open coast of northern California, USA (Carson et al. 2008, Miller et al. 2013), and (2) larvae molt through only 2 larval stages before metamorphosing to postlarvae after approximately $42 \mathrm{~d}$ (Shanks \& Eckert 2005). In this study, we (1) collected embryos from sites with distinctive trace element signatures and reared larvae in seawater from a common source in the laboratory; (2) extracted and analyzed soft tissues from each developmental stage; and (3) compared elemental signatures from the larval and postlarval stages to the embryos obtained from each site. Thus, we determined whether larvae and postlarvae could accurately be assigned to their site of origin, thereby establishing the feasibility of using trace elements in soft tissues for documenting larval dispersal pathways and population connectivity.

\section{MATERIALS AND METHODS}

Ovigerous Petrolisthes cinctipes were collected by hand from 2 sites in 2009 (Bodega Harbor and Fort Bragg) and from 4 sites in 2010 (Bodega Head, Shell Beach, Fort Bragg, and Kibesillah, Fig. 1). Sites were selected from different regions of the coast that have shown distinctive trace element signatures in embryos in previous studies (Carson et al. 2008, Miller et al. 2013). Ovigerous crabs and seawater were collected at each site in late March and early April and transported to Bodega Marine Laboratory (BML) in acid-washed containers. Fifteen crabs were frozen for later analysis of trace elements in embryos. The remaining crabs were transferred to individual mesh cages and placed in $35 \mathrm{l}$ aquaria that were filled with filtered seawater from their collection sites. 


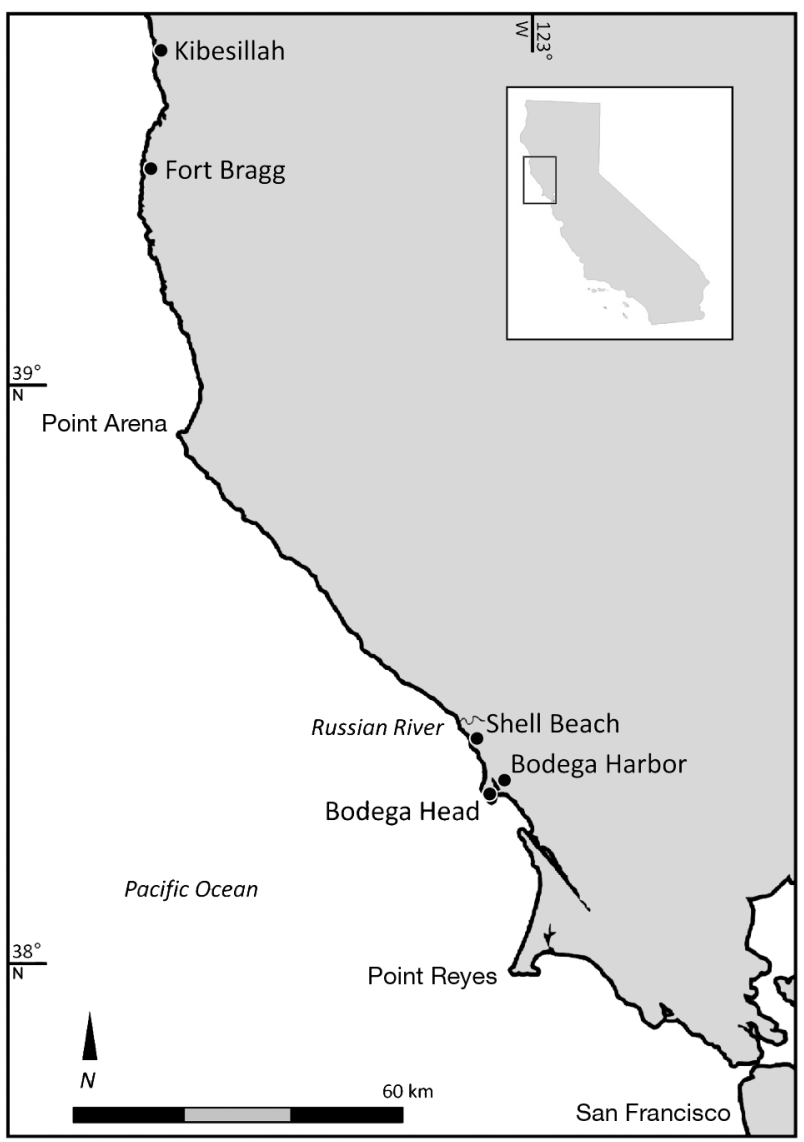

Fig. 1. Porcelain crab Petrolisthes cinctipes collection sites in northern California, USA. Crabs and seawater were collected from Fort Bragg and Bodega Harbor in 2009 and from Kibesillah, Fort Bragg, Shell Beach, and Bodega Head in 2010

Crabs were monitored daily for larval release. Newly hatched larvae were immediately transferred in groups of fewer than 6 individuals to compartments in acid-washed plastic boxes with $95 \mathrm{ml}$ of filtered seawater from Horseshoe Cove, which is located immediately adjacent to BML. Larvae were reared in a $14: 10 \mathrm{~h} \mathrm{~L}: \mathrm{D}$ cycle at $10^{\circ} \mathrm{C}$. They were fed newly hatched Artemia spp. nauplii ad libitum (ca. 230 nauplii per compartment), and every other day water changes were accomplished by moving larvae to new compartments filled with clean seawater, which eliminated a compartment effect. Dead larvae and molts were removed during water changes, and newly hatched Artemia spp. nauplii were added. First-stage larvae molted to the second stage approximately 3 to 4 wk after hatching (19 to $27 \mathrm{~d}$ ), and second-stage larvae molted to postlarvae (the stage at which settlement can occur) approximately 3 to $4 \mathrm{wk}$ later $(21$ to $30 \mathrm{~d})$. Thus, larval development was completed in about 6 to 8 wk ( 40 to $57 \mathrm{~d}$ ).
In 2009, we preserved samples of first- and secondstage larvae and postlarvae to investigate how trace element signatures change between successive stages, and in 2010, we only preserved individuals that successfully molted to postlarvae. Larvae were removed from their compartment using acid-washed porcelain forceps, washed with Milli-Q ultrapure water, and frozen in acid-washed microcentrifuge tubes. Frozen larvae, postlarvae, and ovigerous crabs from each collection site were thawed to room temperature before analysis. Approximately 10 embryos were removed from each crab using acid-washed porcelain forceps and placed in an acid-washed microcentrifuge tube. Larvae and postlarvae were processed individually to extract the soft tissues while leaving the calcified structures intact. Tissues were dissolved by adding $0.5 \mathrm{ml}$ of $2 \mathrm{~N} \mathrm{NaOH}$ (Alfa Aesar, trace element grade) to each sample and heating them in an $80^{\circ} \mathrm{C}$ water bath for $3 \mathrm{~d}$. The resulting solutions were transferred to $50 \mathrm{ml}$ acid-washed centrifuge tubes, leaving the calcified structures in the original microcentrifuge tubes, and diluted to $40 \mathrm{ml}$ using Milli-Q ultrapure water.

Samples were analyzed using an Agilent solutionbased 7500i inductively coupled plasma mass spectrometer (ICP-MS). We analyzed 30 elements, of which 20 occurred at levels at least an order of magnitude higher than background blank measurements to be used. ICP-MS technical details and information on detection limits and elemental standards can be found in Carson et al. (2008). Data were post-processed to eliminate elements that gave clearly erroneous readings (e.g. negative values). Pre-dissolution masses could not be used to standardize data due to small broods in our study species and the risk of contamination during measurement. Instead, we used raw element counts to create proportional scores for each sample (Aruga 1998).

To create proportional scores, ICP-MS raw counts for each element in blanks and samples were averaged, and any elements that were not at least an order of magnitude higher in samples than in blanks were eliminated from further consideration. Element counts were then summed across each sample to get a total count for all elements still in consideration in each sample. Individual element counts were divided by the summed total to create a proportional score for each element in each sample. Proportional scores for each element were then averaged within sites, after which we compared site averages among sites and eliminated elements that had order-of-magnitude differences. We then recalculated the proportional scores and checked for order-of-magnitude differences again. 
Checking for order-of-magnitude differences in elements among sites ensured that each elemental proportion was similarly scaled across sites and our proportional scores were comparable, accurately representing the true differences in elemental concentrations among sites. For example, if 2 sites had raw counts of 1 element that differed by an order of magnitude but very similar raw counts of 20 other elements, their proportional scores would be dramatically different, even though their actual trace element signatures would be virtually identical. By eliminating the elements with order-of-magnitude differences, we can be confident that the trace element signatures created using proportional scores are accurate representations of the actual trace element signatures present in the samples.

Proportional scores do not accurately compare the concentrations of trace elements among samples, but rather the relative proportions of each element among samples. The creation and use of proportional scores is novel for the field of ecology (but see Miller et al. 2013) but is well established in many other fields of science, including chemistry (Aruga 1998, Fushimi et al. 2011), archaeology (Aruga et al. 1999, Kantarelou et al. 2011), environmental engineering (McKenzie et al. 2009), food and health sciences (Chiarenzelli \& Pominville 2008, Korhonova et al. 2009), and geology (Wu et al. 1990). These studies and others like them have successfully used proportional scores to create trace element signatures when the mass of material was unknown, and then used those signatures to classify samples into groups as we do here.

The typical procedure when using elemental signatures to estimate connectivity patterns is to obtain an atlas of natal signatures and then use multivariate machine learning (such as discriminant analysis) to classify post-dispersal individuals. Leave-one-out ('jackknife') reclassification is used to evaluate the precision of the atlas in assigning natal signatures to the correct site (White \& Ruttenberg 2007). We followed this procedure to evaluate the persistence through development of elemental signatures in embryos. We calculated the jackknife reclassification success rate for embryos among sites using quadratic discriminant function analysis (QDA). Although up to 20 elements were available for analysis, we used an optimization procedure to select the suite of elements that afforded the highest reclassification success in each year. We first used univariate analysis of variance tests for among-site differences in each element; elements that were similar ( $p>0.05)$ among sites were excluded from the optimization on the assumption that they would not provide good discrimination. We then calculated the QDA jackknife success rate for every permutation of the remaining elements. Element scores were fourth-root transformed before all analyses to meet the assumptions of normality and equal variances.

From the range of element combinations considered in each year, we identified those that produced reclassification success rates in the 95th percentile for both overall value and mean groupwise success rate, thereby identifying element combinations that had success classifying all of the groups rather than just a few of them. The optimal suite of elements was chosen from within that subset as the suite that had the highest overall jackknife success rate. If no permutation of elements was in the 95th percentile for both categories, we took the permutation that had the highest overall jackknife success rate.

We then created a natal site atlas for each year, using the embryo samples as a training set (the set against which other samples were compared) for QDA to assign postlarvae to a natal site in 2009 and 2010. In 2009, we also used the optimized suite of elements found for embryos to assign stage 1 and 2 larvae and postlarvae to sites of origin, utilizing earlier stages as training sets for later stages to see how well trace element signatures are retained through development. For example, stage 2 larvae were used to create a site atlas to which stage 2 larvae and postlarvae were compared, which enabled us to determine how similar stage 2 larvae were to others from the same natal site (using jackknife reclassification) and to see whether their trace element signatures could assign postlarvae to their correct site of origin. In 2010, we also used postlarvae as a training set to classify themselves to a site of origin. Because QDA does not produce canonical variates that can be used to graphically display the results, we used sliced average variance estimation (SAVE; Pardoe et al. 2007 ) to create figures that display the results of QDA classification in 2 dimensions.

\section{RESULTS}

Embryo samples used to create the natal site atlas in 2009 had an overall jackknife reclassification success to their site of origin of $100 \%$ based on an optimized suite of 6 elements (Fig. 2, Table 1). Although embryos had perfect reclassification success, the reclassification success for larvae and postlarvae was highly variable among stages and between sites (Table 2). Using the embryo site atlas as our training 

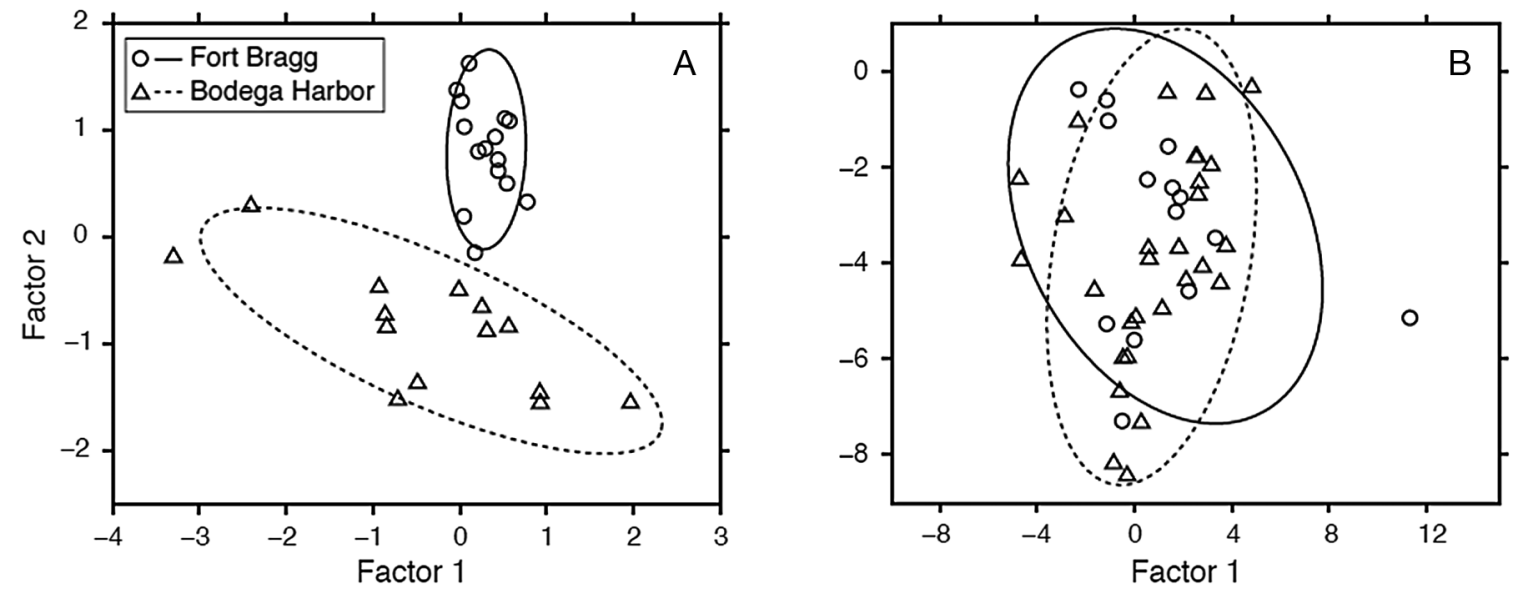

Fig. 2. Petrolisthes cinctipes. Scores plotted to show reclassification success of (A) embryos and (B) postlarvae from 2 sites in 2009 using quadratic discriminant function analysis and the same stage as a training set. Reclassification success to site of origin for embryos was $100 \%$ for both sites. Postlarvae had reclassification successes of $89.7 \%$ correct for Fort Bragg and

$35.7 \%$ correct for Bodega Harbor. Ellipses represent $95 \%$ confidence intervals

set, larvae and postlarvae samples from Bodega Harbor had very low reclassification success, while Fort Bragg samples had a much higher reclassification success (Table 2). The overall reclassification success of $60.5 \%$ correct for postlarvae was driven by the high reclassification success of Fort Bragg samples combined with the unequal sample sizes of postlarvae between sites (Fort Bragg $n=29$, Bodega Harbor $\mathrm{n}=14$; Table 2).

Using larval stages as the training sets provided interesting information on the maintenance of trace element signatures throughout development (Table 2). A site atlas created for stage 1 larvae correctly classified over $90 \%$ of first-stage larvae from both sites. Similarly, using stage 2 larvae as the training set, the atlas correctly classified 86.7 and $78.1 \%$ of secondstage larvae from Bodega Harbor and Fort Bragg, respectively. Using these atlases to classify later stages, however, was met with limited success (Table 2). Using postlarvae as our training set yielded an overall reclassification success of $72.1 \%$, but this again was strongly driven by the high success and greater sample size of Fort Bragg (Fig. 2, Table 2). Because the reclassification successes achieved by using postlarvae as a training set differed between sites, we doubled our number of sites and increased the evenness of our sample sizes in 2010 .

Table 1. Petrolisthes cinctipes. Reclassification success of embryos and postlarvae from 2 sites in 2009 using quadratic discriminant function analysis and embryos as the training set. We used an optimized suite of 6 elements ( $\mathrm{Mg}, \mathrm{V}$, $\mathrm{Cr}, \mathrm{Ni}, \mathrm{As}, \mathrm{Se}$ ) for these reclassifications

\begin{tabular}{|lccccc|}
\hline \multirow{2}{*}{ Site } & $\begin{array}{c}\text { Reclassification } \\
\text { success (\%) } \\
\text { Embryos }\end{array}$ & \begin{tabular}{c} 
Postlarvae \\
\cline { 3 - 5 }
\end{tabular} & & $\begin{array}{c}\text { Potal } \\
\text { Assigned to } \\
\text { Bodega Harbor }\end{array}$ & $\begin{array}{c}\text { Assigned to } \\
\text { Fort Bragg }\end{array}$ \\
\hline Bodega Harbor & 100 & 7.1 & 14 & 1 & 13 \\
Fort Bragg & 100 & 86.2 & 29 & 4 & 25 \\
\hline
\end{tabular}

Table 2. Petrolisthes cinctipes. Reclassification success of discriminant function analysis using earlier developmental stages as training sets for later developmental stages for 2 sites in 2009. Results in bold were determined by using each developmental stage as the training set to reclassify samples of the same stage

\begin{tabular}{|lccccc|}
\hline \multirow{2}{*}{ Training set } & $\mathrm{n}$ & \multicolumn{5}{c|}{ Reclassification success (\%) } \\
\cline { 3 - 6 } & & Embryos & Larvae 1 & Larvae 2 & Postlarvae \\
\hline Bodega Harbor & & & & & \\
Embryos & 14 & $\mathbf{1 0 0}$ & 5.5 & 6.7 & 7.1 \\
Larvae 1 & 18 & - & $\mathbf{9 4 . 4}$ & 60.0 & 71.4 \\
Larvae 2 & 15 & - & - & $\mathbf{8 6 . 7}$ & 54.3 \\
Postlarvae & 14 & - & - & - & $\mathbf{3 5 . 7}$ \\
Fort Bragg & & & & & \\
Embryos & 14 & $\mathbf{1 0 0}$ & 96.7 & 75.6 & 86.2 \\
Larvae 1 & 30 & - & $\mathbf{9 0 . 0}$ & 46.3 & 41.4 \\
Larvae 2 & 40 & - & - & $\mathbf{7 8 . 1}$ & 41.4 \\
Postlarvae & 29 & - & - & - & $\mathbf{8 9 . 7}$ \\
\hline
\end{tabular}


Table 3. Petrolisthes cinctipes. Reclassification success of embryos and postlarvae from 4 sites in 2010 using quadratic discriminant function analysis and embryos as the training set. The optimized element suite contained 13 elements (Mg, Al, Cl, Cr, Ni, Zn, As, Se, Br, Rb, Sr, Mo, Ag)

\begin{tabular}{|lccccc|}
\hline \multirow{2}{*}{ Site } & \multicolumn{2}{c}{$\begin{array}{c}\text { Reclassification } \\
\text { success (\%) }\end{array}$} & Total & $\begin{array}{c}\text { Postlarvae (n) } \\
\text { Assigned } \\
\text { to site }\end{array}$ & $\begin{array}{c}\text { Correctly } \\
\text { classified }\end{array}$ \\
\hline Bodegryos Head & 80.0 & 3.5 & 29 & 3 & 1 \\
Shell Beach & 76.9 & 0 & 13 & 0 & 0 \\
Fort Bragg & 100 & 65.0 & 20 & 46 & 13 \\
Kibesillah & 73.3 & 47.6 & 21 & 34 & 10 \\
\hline
\end{tabular}

Magnesium and vanadium varied greatly in samples from both sites. For 10 of the 13 elements in our optimized suite in 2010, the southernmost (Bodega Head) and northernmost (Kibesillah) sites were more similar to each other than to either of the other sites (Shell Beach and Fort Bragg; Fig. 5). All elements in the optimized suite each year were significantly different among sites $(p<0.05)$. Proportional scores of all elements analyzed differed among developmental stages

In 2010, embryo samples had an average reclassification success to their site of origin of $81.4 \%$, ranging from $100 \%$ correct (Fort Bragg) to $73.3 \%$ correct (Kibesillah), based on an optimized suite of 13 elements (Table 3, Fig. 3). As in 2009, reclassifications of postlarvae were much lower, with an overall success rate of $28.9 \%$, ranging from $65 \%$ correct (Fort Bragg) to $0 \%$ correct (Shell Beach) based on the same optimized suite of elements. Of 83 postlarvae, only 3 were assigned to Bodega Head (1 correctly), and none was assigned to Shell Beach (Table 3). Most postlarvae were assigned to Fort Bragg, although this site contributed the second fewest postlarvae that year. Using the trace element signatures of postlarvae as a training set to assign postlarvae to a site of origin resulted in a higher success rate (51.8\% correct), though individual sites ranged from $33.3 \%$ correct (Shell Beach) to $62.1 \%$ correct (Bodega Head; Fig. 3).

Proportional scores of elements ranged widely each year, with Fort Bragg having higher chromium, nickel, and arsenic than Bodega Harbor in 2009 (Fig. 4). in both years, with the possible exception of bromine (Fig. S1 in the Supplement at www.int-res.com/ articles/suppl/m481p001_supp.pdf). Trace element proportions also differed between years, as we have previously shown for 15 sites along the coast in our study region (Miller et al. 2013; see also Fig. S1).

\section{DISCUSSION}

Porcelain crab larvae did not reliably retain trace element signatures in their soft tissues as they developed from embryos to postlarvae, but postlarvae from different sites could be distinguished from each other. This suggests that soft tissue trace element signatures could be useful in determining how many sites, rather than which sites, contribute to a cohort of settlers (sensu Standish et al. 2011).

The reclassification success of embryos to natal sites was high in both years of the study, indicating that the natal atlas in each year comprised sites with
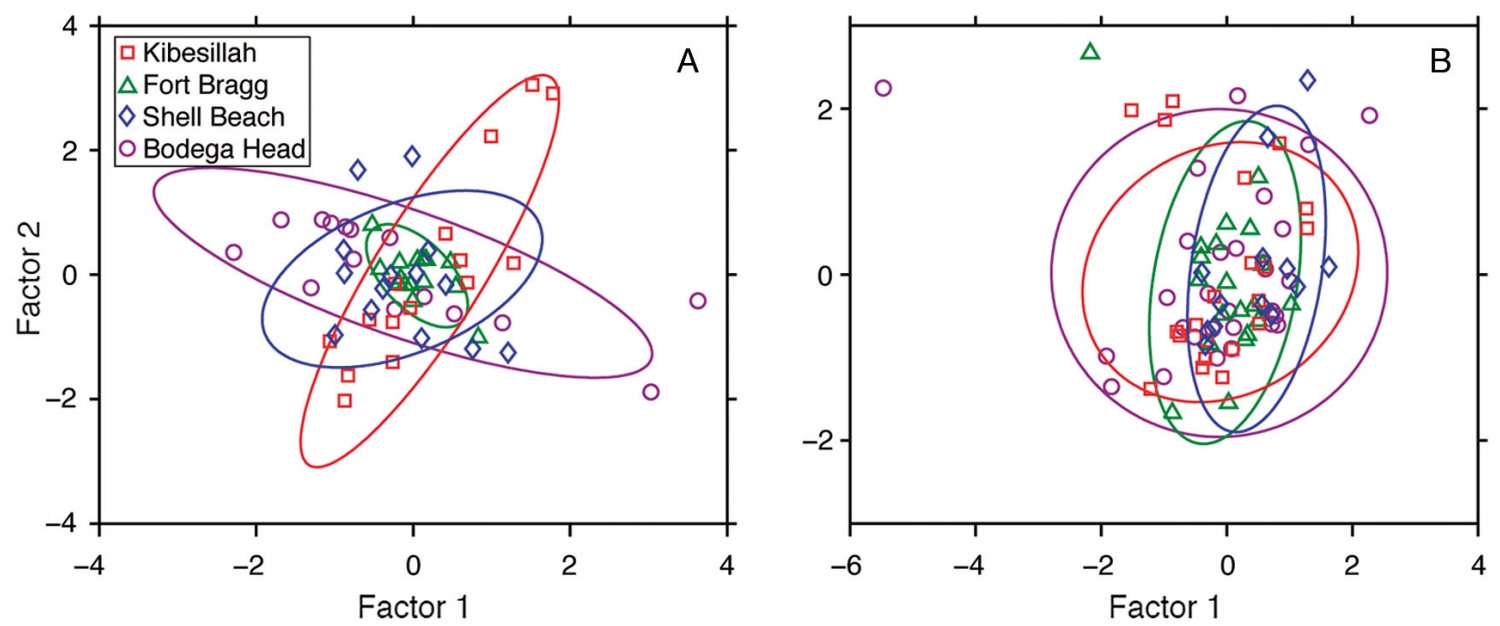

Fig. 3. Petrolisthes cinctipes. Scores plotted to show reclassification success of (A) embryos and (B) postlarvae from 4 sites in 2010 using quadratic discriminant function analysis and the same stage as a training set. Ellipses represent 95\% confidence intervals 

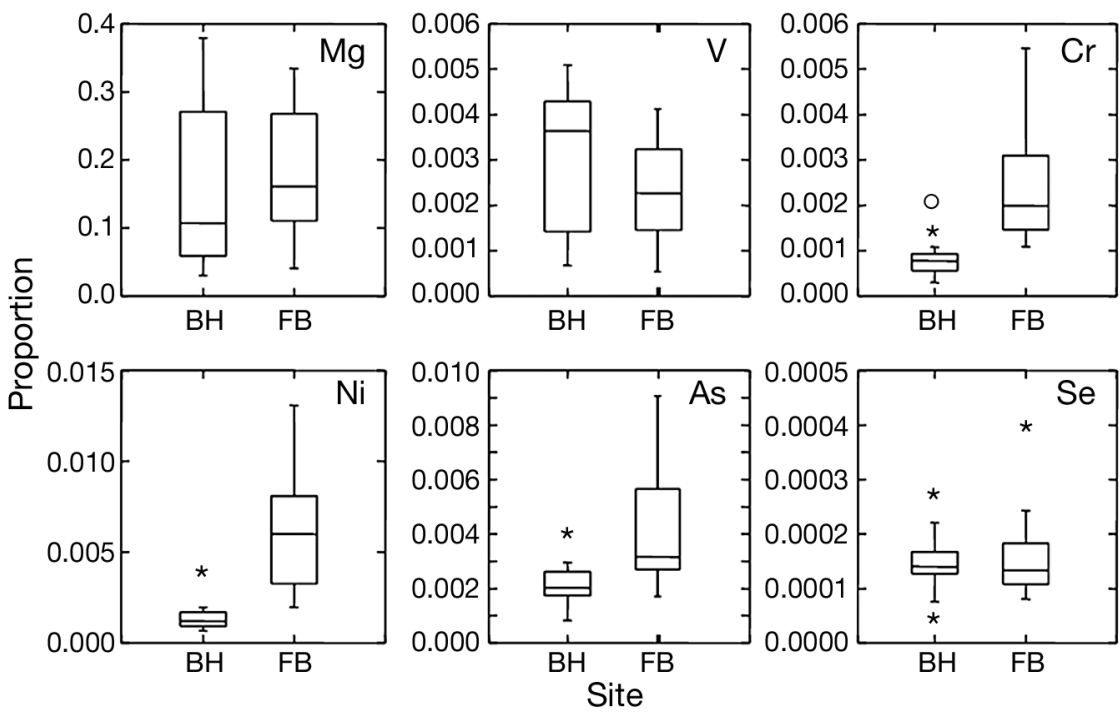

Fig. 4. Petrolisthes cinctipes. Average proportional score for each element in the optimized suite of elements for embryo samples from Bodega Harbor (BH) and Fort Bragg (FB) in 2009. Horizontal lines: median value; boxes: interquartile range $(\mathrm{IQR})$; whiskers: values $<1.5 \times \mathrm{IQR}$. Asterisks and open circles denote outliers $(>1.5 \times \mathrm{IQR})$ and extreme outliers $(>3 \times \mathrm{IQR})$, respectively. Proportional scores do not sum to 1 because not all elements were part of the optimized element suite distinctive elemental signatures (Carson et al. 2008). However, using this atlas we were unable to correctly assign high percentages of postlarval settlers to their sites of origin with the exception of 1 site in 1 year (Fort Bragg in 2009). Fort Bragg was the only site for which we have data in both 2009 and 2010, and its reclassification successes differed by almost $25 \%$ between years. These widely varying results and overall poor reclassification successes indicate that trace element signatures in soft tissues cannot be used reliably to determine the origins of settlers for this species.

The mismatch between the trace element signatures of embryos and postlarvae could indicate that either (1) our experimental design disrupted the retention of natal signatures that would have occurred naturally in the field; or (2) larvae do not retain natal

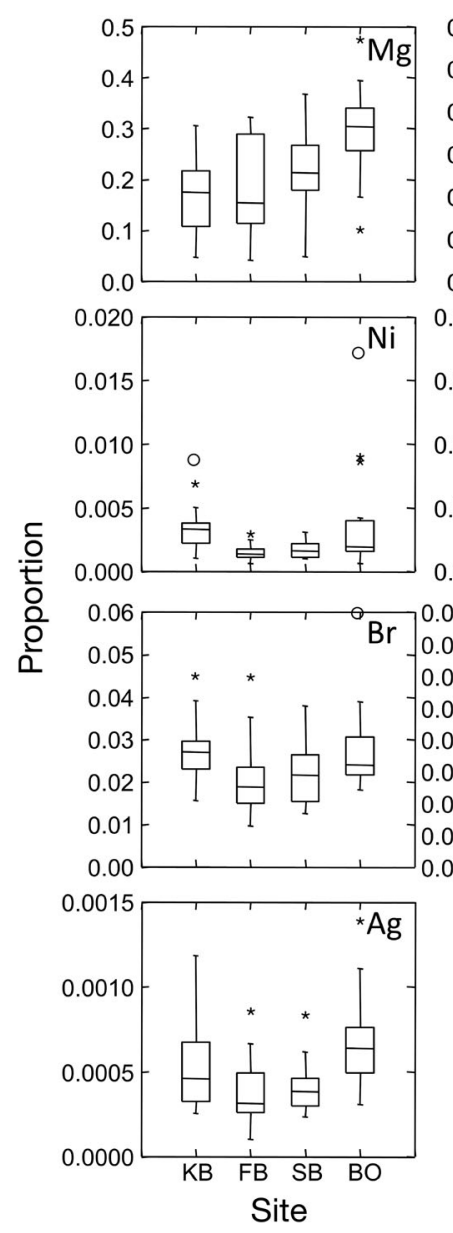

Fig. 5. Petrolisthes cinctipes. Average proportional score for each element in the optimized suite of elements for embryo samples from 4 sites (KB: Kibesillah; FB: Fort Bragg; SB: Shell Beach; BO: Bodega Head) arranged from north to south in 2010. See Fig. 4 for a description of box plot symbols 
signatures throughout their development. Although we simulated larval mixing in the nearshore by rearing larvae in a common garden, larvae may stay close to their natal sites where they would be exposed to water masses that are much more similar to their natal sites than in our study (Morgan et al. 2009, Morgan \& Fisher 2010). This would result in signatures that are similar to the water in which larvae grow, so the settlers in our study would have been assigned to Bodega Head, given that they were reared in water collected from this site. Because only 3 settlers were assigned to Bodega Head in 2010 and only 1 of them was assigned correctly (Table 3 ), we can reject the hypothesis that larvae assimilate trace element signatures from the water mass in which they develop. Furthermore, most postlarvae in 2010 were assigned to the 2 northern sites, Fort Bragg and Kibesillah, which are located over $150 \mathrm{~km}$ north of Bodega Head where the seawater used to raise the larvae was obtained. Therefore, larvae in our study did not retain embryonic elemental signatures throughout their development.

Identifying specific elements that are retained throughout larval development is an important next step toward determining whether soft tissue trace element signatures could be used to determine natal origins for other species that have shorter pelagic larval durations, occur in warm waters, or live in habitats that have stronger trace element signals, such as estuaries. This is particularly important because most trace elements vary spatially along the coast (Figs. $4 \& 5$ ), so if an element were retained, it would likely be useful for discriminating among sites or regions. Future laboratory studies should also aim to determine the relative importance of the multiple ways larvae can incorporate trace elements, including uptake through food, absorption through water, and transfer from parents, and test specific elements that have shown promise for retention in previous studies (e.g. selenium; Anastasia et al. 1998). Understanding the pathway through which larvae incorporate trace elements will help researchers identify elements that are likely to be retained; for example, rare earth elements might be absorbed through water, while elements used in biological processes might be transferred from parents. Investigations such as these will provide the information necessary to determine whether trace element signatures in soft tissues could be useful to determine the natal origins of some taxa.

Our data revealed changes in the trace element signatures of larvae between each developmental stage. Importantly, all larval stages had very high (up to $100 \%$ ) reclassification success when we used the same stage to create a trace element atlas in 2009 (Table 2), revealing a new way to use trace element signatures to investigate larval dispersal. Instead of using a natal site atlas to identify the source populations that contributed to a settler pool at a given site (not possible because natal signatures change during larval development), researchers could conduct a contribution analysis.

Because postlarvae from each site possessed a distinctive elemental signature (albeit not the same signature they possessed as embryos), determining the number of distinct trace element signatures present in a sample of settled postlarvae at a site could reveal how many natal sites contributed to the settler pool, even though the sites of origin would be unknown. This method, however, has several assumptions that must be met. Trace element signatures must be different among natal sites and the variation in signatures among sites must be greater than the variation in signatures among individuals. Additionally, individuals that travel through multiple regions could assimilate signatures in both regions, creating uncertainty in natal assignments.

White et al. (2008) provided a method for determining the number of sources and their relative contribution using Markov chain-Monte Carlo combined with parsimony-based model selection. Essentially this method defines a source signature based on the distribution of the data: the natal signatures from a given source should follow a multivariate distribution with a particular mean and covariance, and the method finds the smallest number of sources (i.e. distinct means and covariances) that provides a good fit to the observed distribution of signatures. Thus the method relies on defining a 'source' statisticallyas a distinct mean and covariance in multivariate space-rather than geographically with a known signature. However, this approach can yield conclusions similar to (but somewhat less precise than) an analysis in which a true natal atlas is available (White et al. 2008). Standish et al. (2011) applied this method to an open-coast fish population in which it is not possible to sample all natal sites, and we are currently working to develop this analysis for Petrolisthes cinctipes (S. H. Miller \& J. W. White unpubl. data).

Even if these assumptions cannot be met for settling postlarvae of some species, this technique could still be useful for determining the dispersal trajectories of early larval stages. Groups of early-stage larvae caught in the water column could be analyzed to determine whether certain locations contained 
larvae from many source populations and thus could be serving as larval nurseries. Recognizing how many sources contributed to a cohort of larvae in a nursery area and identifying locations that serve as larval nurseries would be invaluable, particularly for populations that are geographically isolated or targeted for inclusion in a marine protected area. Investigators also could compare trace element signatures of embryos and field-caught first-stage larvae to determine initial dispersal trajectories and rates (DiBacco \& Chadwick 2001). If larvae assimilate trace elements directly from seawater during their pelagic development, as has been shown in some fishes (Swearer et al. 1999, Hamilton et al. 2008), comparing the signatures of later stage field-caught larvae to signatures of coastal water masses could reveal broad dispersal trajectories and nursery locations, such as offshore versus nearshore waters.

Our study provides critical information concerning the development of a natural trace element tag for marine larvae. The use of these tags to determine connectivity among known populations has thus far been restricted to the few species that retain significant calcium carbonate structures throughout larval development, but trace element signatures in soft tissues can also be useful tools for understanding population connectivity. Although trace element signatures were not retained in the soft tissues of our study species throughout its larval development, other species might be better suited for this technique. Nevertheless, the signatures of larvae in our study from individual sites appear to change in similar ways, providing researchers with a useful method for determining how many sources contribute to the settler pool at a site. This finding greatly increases the number of species for which trace element signatures can provide information about population connectivity and source-sink dynamics in the sea.

Acknowledgements. We thank C. Lord and W. Dillon for help with field collections, M. Evans for laboratory assistance, and T. Young for ICP-MS availability. T. Hill, J. Largier, and C. Lord provided useful comments on the manuscript. This research was funded by California Sea Grant (NA08AR4170669) and the National Science Foundation (OCE-0326110).

\section{LITERATURE CITED}

Anastasia JR, Morgan SG, Fisher NS (1998) Tagging crustacean larvae: assimilation and retention of trace elements. Limnol Oceanogr 43:362-368

Anderson SL, Cherr GN, Morgan SG, Vines CA and others (2006) Integrating contaminant responses in indicator saltmarsh species. Mar Environ Res 62:S317-S321
Aruga R (1998) Closure of analytical chemical data and multivariate classification. Talanta 47:1053-1061

Aruga R, Mirti P, Casoli A, Palla G (1999) Classification of ancient proteinaceous painting media by the joint use of pattern recognition and factor analysis on GC/MS data. Fresenius J Anal Chem 365:559-566

Becker BJ, Fodrie FJ, McMillan PA, Levin LA (2005) Spatial and temporal variation in trace elemental fingerprints of mytilid mussel shells: a precursor to invertebrate larval tracking. Limnol Oceanogr 50:48-61

Becker BJ, Levin LA, Fodrie FJ, McMillan PA (2007) Complex larval connectivity patterns among marine invertebrate populations. Proc Natl Acad Sci USA 104: 3267-3272

> Carlon DB, Olson RR (1993) Larval dispersal distance as an explanation for adult spatial pattern in two Caribbean reef corals. J Exp Mar Biol Ecol 173:247-263

Carson HS (2008) The larval dispersal of California marine invertebrates. PhD dissertation, University of California, Davis, CA

Carson HS, Morgan SG, Green PG (2008) Fine-scale chemical fingerprinting of an open coast crustacean for the assessment of population connectivity. Mar Biol 153: 327-335

Chiarenzelli J, Pominville C (2008) Bottled water selection and health considerations from multi-element analysis of products sold in New York state. J Water Health 6: 505-512

DiBacco C, Chadwick DB (2001) Assessing the dispersal and exchange of brachyuran larvae between regions of San Diego Bay, California and nearshore coastal habitats using elemental fingerprinting. J Mar Res 59:53-78

> DiBacco C, Levin LA (2000) Development and application of elemental fingerprinting to track the dispersal of marine invertebrate larvae. Limnol Oceanogr 45:871-880

Fushimi A, Saitoh K, Fujitani Y, Hasegawa S, Takahashi K, Tanabe K, Kobayashi S (2011) Organic-right nanoparticles (diameter: 10-30 nm) in diesel exhaust: fuel and oil contribution based on chemical composition. Atmos Environ 45:6326-6336

Hamilton SL, Regetz J, Warner RR (2008) Postsettlement survival linked to larval life in a marine fish. Proc Natl Acad Sci USA 105:1561-1566

Hayes JL (1991) Elemental marking of arthropod pests in agricultural systems: single and multigenerational marking. Southwest Entomol 14:37-47

> Jones GP, Milicich MJ, Emslie MJ, Lunow C (1999) Selfrecruitment in a coral reef fish population. Nature 402: 802-804

Kantarelou V, Ager FJ, Eugenidou D, Chaves F and others (2011) X-ray fluorescence analytical criteria to assess the fineness of ancient silver coins: application on Ptolemaic coinage. Spectrochim Acta B 66:681-690

Kingsford MJ, Leis JM, Shanks AL, Lindeman KC, Morgan SG, Pineda J (2002) Sensory environments, larval abilities and local self-recruitment. Bull Mar Sci 70:309-340

Korhonova M, Hron K, Klimcikova D, Muller L, Bednar P, Bartak P (2009) Coffee aroma-statistical analysis of compositional data. Talanta 80:710-715

Levin LA, Huggett D, Myers P, Bridges T, Weaver J (1993) Rare-earth tagging methods for the study of larval dispersal by marine invertebrates. Limnol Oceanogr 38:346-360

> Marshall DJ, Morgan SG (2011) Ecological and evolutionary consequences of linked life-history stages in the sea. Curr Biol 21:R718-R725 
McKenzie ER, Money JE, Green PG, Young TM (2009) Metals associated with stormwater-relevant brake and tire samples. Sci Total Environ 407:5855-5860

Miller SH, Morgan SG (2013) Interspecific differences in depth preference: regulation of larval transport in an upwelling system. Mar Ecol Prog Ser 476:301-306

Miller SH, Morgan SG, White JW, Green PG (2013) Interannual variability in an atlas of trace element signatures for determining population connectivity. Mar Ecol Prog Ser 474:179-190

Mohler JW (1997) Immersion of larval Atlantic salmon in calcein solutions to induce a non-lethally detectable mark. N Am J Fish Manag 17:751-756

Moran AL (2000) Calcein as a marker in experimental studies of newly hatched gastropods. Mar Biol 137: 893-898

Morgan SG, Fisher JL (2010) Larval behavior regulates nearshore retention and offshore migration in an upwelling shadow and along the open coast. Mar Ecol Prog Ser 404:109-126

Morgan SG, Fisher JL, Miller SH, McAfee ST, Largier JL (2009) Nearshore larval retention in a region of strong upwelling and recruitment limitation. Ecology 90:3489-3502

Olson RR (1985) The consequences of short-distance larval dispersal in a sessile marine invertebrate. Ecology 66: 30-39

Pardoe I, Yin X, Cook RD (2007) Graphical tools for quadratic discriminant analysis. Technometrics 49:172-183

Queiroga H, Blanton J (2005) Interactions between behaviour and physical forcing in the control of horizontal transport of decapod crustacean larvae. Adv Mar Biol 47: $107-214$

Shanks AL, Eckert GL (2005) Population persistence of California current fishes and benthic crustaceans: a marine drift paradox. Ecol Monogr 75:505-524

Shanks AL, Shearman RK (2009) Paradigm lost? Cross-shelf distributions of intertidal invertebrate larvae are unaffected by upwelling or downwelling. Mar Ecol Prog Ser 385:189-204

Smalling KL, Morgan SG, Kuivila KK (2010) Accumulation of current-use and organochlorine pesticides in crab

Editorial responsibility: Paul Snelgrove, St. John's, Newfoundland and Labrador, Canada embryos from northern California, USA. Environ Toxicol Chem 29:2593-2599

Standish JD, White JW, Warner RR (2011) Spatial pattern of natal signatures in the otoliths of juvenile kelp rockfish along the Californian coast. Mar Ecol Prog Ser 437: 279-290

Strathmann RR, Hughes TP, Kuris AM, Lindeman KC, Morgan SG, Pandolfi JM, Warner RR (2002) Evolution of local recruitment and its consequences for marine populations. Bull Mar Sci 70:377-396

Swearer SE, Caselle JE, Lea DW, Warner RR (1999) Larval retention and recruitment in an island population of a coral-reef fish. Nature 402:799-802

Thorrold SR, Jones GP, Hellberg ME, Burton RS and others (2002) Quantifying larval retention and connectivity in marine populations with artificial and natural markers. Bull Mar Sci 70:291-308

> Thorrold SR, Zacherl DC, Levin LA (2007) Population connectivity and larval dispersal using geochemical signatures in calcified structures. Oceanography 20:80-89

Walther BD, Thorrold SR (2006) Water, not food, contributes the majority of strontium and barium deposited in the otoliths of a marine fish. Mar Ecol Prog Ser 311:125-130

White JW, Ruttenberg BI (2007) Discriminant function analysis in marine ecology: some oversights and their solutions. Mar Ecol Prog Ser 329:301-305

White JW, Standish JD, Thorrold SR, Warner RR (2008) Markov chain Monte Carlo methods for assigning larvae to natal sites using natural geochemical tags. Ecol Appl 18:1901-1913

Wu L, Vomocil JA, Childs SW (1990) Pore size, particle size, aggregate size, and water retention. Soil Sci Soc Am J 54:952-956

Young CM (1995) Behavior and locomotion during the dispersal phase of larval life. In: McEdward L (ed) Ecology of marine invertebrate larvae. CRC Press, Boca Raton, FL, p 249-278

Zacherl DC, Manriquez PH, Paradis G, Day RW and others (2003) Trace elemental fingerprinting of gastropod statoliths to study larval dispersal trajectories. Mar Ecol Prog Ser 248:297-303

Submitted: June 11, 2012; Accepted: March 12, 2013

Proofs received from author(s): April 29, 2013 